\title{
A RAZÃo SEM Voto: \\ A FUNÇÃO REPRESENTATIVA E MAJORITÁRIA DAS CORTES CONSTITUCIONAIS
}

LUÍS ROBERTO BARROSO ${ }^{\dagger}$

\section{UM DOSSIÊ SOBRE TAXONOMIA DAS GERAÇÕES DE DIREITOS}

Palavras-Chave: Cortes Constitucionais; Representação Política; Contramajoritarismo.

KEYWORDS: Constitutional Courts; Political Representation; Countermajoritarism.

${ }^{\dagger}$ Ministro do Supremo Tribunal Federal. Professor Titular de Direito Constitucional da Universidade do Estado do Rio de Janeiro. Mestre em Direito pela Universidade de Yale. Doutor e Livre-Docente pela Universidade do Estado do Rio de Janeiro. Professor Visitante em Université de Poitiers, França (2010) e em Harvard University (2011). 


\section{SUMÁRIO:}

I. INTRODUÇÃO ...........................................................................................519

II. Algumas CONCEPÇÕES DE MARK TUSHNET ..................................520

III. A JURISDIÇÃo CONSTITUCIONAL ..................................................522

IV. O PAPEL CONTRAMAJORITÁRIO DAS CORTES SUPREMAS...............523

V. A CRISE dA REPRESENTAÇÃo POLÍTICA...........................................526

VI. O PAPEL REPRESENTATIVO DO SUPREMO TRIBUNAL FEDERAL ....528

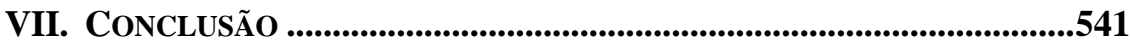

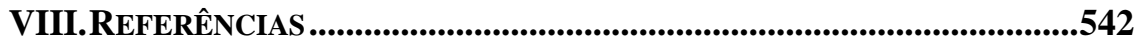

\section{TABLE OF CONTENTS:}

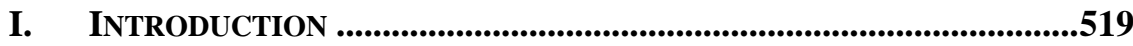

II. SOME CONCEPTIONS OF MARK TUSHNET .....................................520

III. THE JUDICIAL REVIEW.........................................................................522

IV. The Countermajoritarian Role OF SUPREME CouRTS ..........523

V. THE CRISIS OF POLITICAL REPRESENTATION .................................526

VI. The RePresentative Role OF BRAZILIAN SUPREME COURT ....528

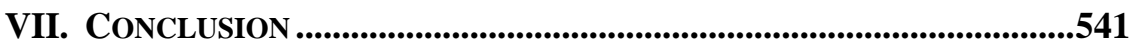

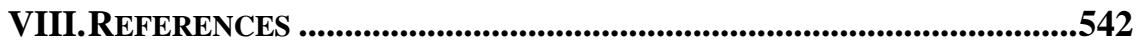




\section{INTRODUÇÃO}

Meus caminhos acadêmicos e os do Professor Mark Tushnet se cruzaram algumas vezes ao longo dos anos. Ainda na década de 80 , no início da minha carreira como professor, li textos dele quando era uma figura proeminente no movimento conhecido como Critical Legal Studies. Bem mais à frente, passamos a nos encontrar, aqui e ali, em seminários e eventos acadêmicos. Durante minha estada como visiting scholar em Harvard, em 2011, tivemos oportunidade de trocar ideias em mais de uma ocasião. Em dois encontros em universidades diversas, tivemos chance de debater diretamente, integrando um mesmo painel. $\mathrm{Na}$ primeira delas, na Pontifícia Universidade Católica, em Porto Alegre, Brasil, discutimos o papel dos precedentes no direito em geral, e no direito constitucional em particular. Os sistemas jurídicos do common law e do civil law percorreram uma trajetória de relativa aproximação nos últimos tempos. A lei escrita, votada pelo Legislativo, passou a ter importância muito maior em países como Estados Unidos, Reino Unido e Canadá; por outro lado, o respeito aos precedentes, decorrentes de decisões judiciais dos tribunais superiores, passou a ter muito maior significação em países como Brasil, México ou Chile. Sou defensor da valorização e da observância ampla da jurisprudência, em nome da igualdade, da segurança jurídica e da maior eficiência do sistema judicial. Isso, naturalmente, envolve uma certa mudança cultural dos juristas formados na tradição romano-germânica. Nessa matéria, nossas posições eram substancialmente concordantes.

Nosso outro debate foi na Universidade de Harvard, em Cambridge, nos Estados Unidos, a propósito das relações entre direito e política e, particularmente, do papel de supremas cortes e tribunais constitucionais em uma democracia. Nessa matéria, em relação a algumas questões, tínhamos pontos de observação diferentes. Tais divergências não eram propriamente filosóficas ou ideológicas. Em verdade, ao menos em boa parte, elas podem ser creditadas à experiência recente de nossos países no tocante à jurisdição constitucional. De fato, nos Estados Unidos, começando no período da presidência de Richard Nixon, mas, sobretudo, após a ascensão de Ronald Reagan, a Suprema Corte americana sofreu o impacto de uma onda conservadora, colocando em risco certas conquistas trazidas pela jurisprudência progressista que teve como símbolo a Corte Warren. No Brasil, por outro lado, após a redemocratização, em 1988, e, sobretudo, a partir de meados dos anos 2000, o Supremo Tribunal Federal tornou-se um importante instrumento de proteção dos direitos fundamentais e de avanço social. Em diversos momentos, o Tribunal desempenhou papel decisivo ao contrabalançar a tradição de hegemonia 
do Executivo e ao superar a inércia do Congresso Nacional em temas importantes.

O texto que se segue é, de certa forma, o aprofundamento deste último diálogo, relacionado especialmente às funções desempenhadas pela jurisdição constitucional em regimes democráticos ${ }^{1}$. Antes de expor as minhas próprias ideias e de relatar alguns aspectos da experiência brasileira, preparei um capítulo inicial com a síntese sumária de algumas posições de Mark Tushnet, colhidas em três de seus principais livros.

\section{Algumas Concepções de Mark Tushnet}

Em seu livro Taking the Constitution away from the Courts ${ }^{2}$, publicado em 1999, Mark Tushnet questiona duramente a tradição americana de jurisdição constitucional (judicial review $w^{3}$ ) e de supremacia judicial na interpretação e aplicação da Constituição. Sustenta que, ao contrário do que acredita o conhecimento convencional - ou, pelo menos, a visão liberal-progressista -, a defesa dos direitos fundamentais tem melhores guardiões nos cidadãos, na política e no Legislativo do que na Suprema Corte. Radicalizando o argumento um pouco além, Tushnet afirma que se a Suprema Corte americana anunciasse que não mais exerceria a jurisdição constitucional, tal fato faria pouca diferença para a sociedade e para o povo americano, inclusive no que diz respeito à proteção de seus direitos. O livro defende um chamado constitucionalismo popular ${ }^{4}$, que retire a Constituição dos tribunais e de sua visão elitista do direito constitucional, e a devolva para o povo e seus representantes. De passagem, Tushnet critica os autores liberais e progressistas defensores

${ }^{1} \mathrm{O}$ presente texto é uma adaptação de um trabalho maior, intitulado $A$ razão sem voto: o Supremo Tribunal Federal e o governo da maioria, ainda inédito.

2 TUSHNET, Mark. Taking the Constitution away from the Courts. Princeton, NJ: Princeton University Press, 1999.

${ }^{3}$ Normalmente, a expressão judicial review é traduzida como controle de constitucionalidade. Optei, no entanto, pela expressão mais abrangente jurisdição constitucional. É que as supremas cortes ou tribunais constitucionais desempenham um papel mais abrangente do que apenas declarar leis inconstitucionais ou não, como a interpretação da legislação conforme a Constituição e a superação de eventuais omissões inconstitucionais, para citar dois exemplos.

4 Tushnet fala em populist constitutionalism. Em alguns países, porém, o termo populista tem uma conotação negativa, identificando políticas demagógicas de curto prazo e efeitos negativos ao longo do tempo. 
do judicial review, por terem medo do povo e de suas decisões, e acreditarem na ilusão "de que a Suprema Corte pode nos salvar de nós mesmos".

Em outro livro, intitulado Weak Courts, Strong Rights ${ }^{5}$, publicado em 2008, Mark Tushnet explora dois temas diversos, procurando fazer uma importante conexão entre eles: o papel das cortes constitucionais em uma democracia e as condições de possibilidade de se garantirem direitos sociais na Constituição. Para os propósitos visados no presente artigo, merece destaque a distinção que o autor faz entre forma forte e forma fraca de jurisdição constitucional. O modelo forte é o praticado nos Estados Unidos e nos países que seguiram a fórmula que lá prevalece, desde Marbury vs. Madison, julgado em 1803. Nele, a interpretação da Constituição feita pela Suprema Corte é final e insuscetível de revisão. Ao revés, no que denomina de modelo fraco, o Legislativo ou o Executivo podem eventualmente rejeitar ou superar decisões proferidas pela corte suprema. Os modelos que invoca são a Nova Zelândia, o Reino Unido e o Canadá. No Canadá, particularmente, duas previsões constitucionais dão lugar a uma fórmula "dialógica" de jurisdição constitucional, permitindo, como o nome sugere, uma conversa entre instituições judiciais e legislativas acerca de determinados temas. Na prática, não há precedentes relevantes na matéria no próprio Canadá. Porém, o conceito de diálogo institucional ou diálogo constitucional permitiu a adoção de "ilhas" de controle fraco em sistemas que adotam o controle forte, como bem intuiu Tushnet.

Por fim, em Why the Constitution Matters ${ }^{6}$, publicado em 2010, Mark Tushnet procura desmistificar a crença, largamente arraigada na teoria constitucional, de que o principal papel de uma Constituição é a definição e a proteção dos direitos fundamentais. Segundo ele, a Constituição é verdadeiramente importante, não porque protege determinados direitos fundamentais, mas porque estrutura o funcionamento da política. É no âmbito da política ordinária, e não da Constituição, que se tomam as grandes decisões que repercutem concretamente sobre a vida das pessoas. O processo legislativo e o Congresso são muito mais influentes do que o processo judicial e as decisões da Suprema Corte, segundo crê. Mais que isso, Tushnet procura demonstrar, com variados exemplos, como a política influencia a própria Suprema Corte e sua definição de quais sejam os direitos fundamentais. Nesse ponto, ele endossa o

5 TUSHNET, Mark. Weak Courts, Strong Rights: Judicial Review and Social Welfare Rights in Comparative Constitutional Law. Princeton, NJ: Princeton University, 2008. 6 TUSHNET, Mark. Why the Constitution matters. New Haven, CN: Yale University Press, 2010. 
argumento de que, no mais das vezes, a Suprema Corte se alinha à vontade da maioria nacional ou, pelo menos, ao sentimento que se tornou prevalecente nas elites. E conclui que tratar a interpretação constitucional como uma forma de política é algo positivo.

Postas estas ideias, cabe contrastá-las com o que se passa em um mundo diverso do americano.

\section{A JURISDIÇÃo CONSTITUCIONAL}

Ao longo da segunda metade do século XX, os países da Europa continental e os que seguem a tradição romano-germânica, de uma maneira geral, assistiram a uma importante mudança de paradigma em relação ao desenho e à teoria constitucionais: a passagem do Estado legislativo de direito para o Estado constitucional de direito 7 . No modelo antigo, a Constituição era compreendida, essencialmente, como um documento político, cujas normas não eram aplicáveis diretamente, ficando na dependência de desenvolvimento pelo legislador ou pelo administrador. Tampouco existia o controle de constitucionalidade das leis pelo Judiciário - ou, onde existia, era tímido e pouco relevante. Nesse ambiente, vigorava a centralidade da lei e a supremacia do parlamento. No Estado constitucional de direito, a Constituição passa a valer como norma jurídica. A partir daí, ela não apenas disciplina o modo de produção das leis e atos normativos, como estabelece determinados limites para o seu conteúdo, além de impor deveres de atuação ao Estado. Nesse novo modelo, vigora a centralidade da Constituição e a supremacia judicial, como tal entendida a primazia de um tribunal constitucional ou suprema corte na interpretação final e vinculante das normas constitucionais.

A expressão jurisdição constitucional designa a interpretação e aplicação da Constituição por órgãos judiciais. No caso brasileiro - e dos países que seguem o modelo americano em geral -, essa competência é exercida por todos os juízes e tribunais, situando-se o Supremo Tribunal Federal no topo do sistema. A jurisdição constitucional compreende duas atuações particulares. A primeira, de aplicação direta da Constituição às situações nela contempladas. Por exemplo, o reconhecimento de que determinada competência é do governo federal e não dos estados, ou o

${ }^{7}$ Sobre o tema, v. FERRAJOLI, Luigi. Pasado y futuro Del Estado de Derecho. In:

Miguel Carbonell (Coord.). Neoconstitucionalismo(s). Madrid: Editora Trotta, 2003, p. 14-17; e ZAGREBELSKY, Gustavo. El Derecho Dúctil: Ley, Derechos, Justicia. 6⿳a ed. Madrid: Editora Trotta, 2005, p. 21-41. 
direito à liberdade de expressão sem censura prévia. Também se insere na aplicação direta da Constituição a competência, mais complexa e politicamente delicada, de sanar omissões inconstitucionais, nos casos em que a ausência de norma regulamentadora frustra o exercício de um direito fundamental. A segunda atuação envolve a aplicação indireta da Constituição, que se dá quando o intérprete a utiliza como parâmetro para aferir a validade de uma norma infraconstitucional (controle de constitucionalidade) ou para atribuir a ela o melhor sentido, em meio a diferentes possibilidades (interpretação conforme a Constituição). Em suma: a jurisdição constitucional compreende o poder exercido por juízes e tribunais na aplicação direta da Constituição, no desempenho do controle de constitucionalidade das leis e dos atos do Poder Público em geral e na interpretação do ordenamento infraconstitucional conforme a Constituição.

Do ponto de vista político-institucional, o desempenho da jurisdição constitucional por supremas cortes ou tribunais constitucionais mundo afora envolve dois tipos de atuação: a contramajoritária e a representativa. A atuação contramajoritária é um dos temas mais analisados na teoria constitucional, que há muitas décadas discute a legitimidade democrática da invalidação de atos do Legislativo e do Executivo por órgão jurisdicional. Já a função representativa tem sido largamente ignorada pela doutrina e pelos formadores de opinião em geral. Nada obstante isso, em algumas partes do mundo, e destacadamente no Brasil, este segundo papel se tornou não apenas mais visível como, circunstancialmente, mais importante. O presente capítulo procura lançar luz sobre esse fenômeno, que tem passado curiosamente despercebido, apesar de ser, possivelmente, a mais importante transformação institucional da última década.

\section{O PAPEl CONTRAMAJORITÁrio das Cortes Supremas}

O Supremo Tribunal Federal, como as cortes constitucionais em geral, exerce o controle de constitucionalidade dos atos normativos, inclusive os emanados do Poder Legislativo e da chefia do Poder Executivo. No desempenho de tal atribuição, pode invalidar atos do Congresso Nacional - composto por representantes eleitos pelo povo brasileiro - e do Presidente da República, eleito com mais de meia centena de milhões de votos. Vale dizer: onze Ministros do STF (na verdade seis, pois basta a maioria absoluta), que jamais receberam um voto popular, podem sobrepor a sua interpretação da Constituição à que foi feita por agentes

políticos investidos de mandato representativo e legitimidade 
democrática. A essa circunstância, que gera uma aparente incongruência no âmbito de um Estado democrático, a teoria constitucional deu o apelido de "dificuldade contramajoritária" 8 .

A despeito de resistências teóricas pontuais ${ }^{9}$, esse papel contramajoritário do controle judicial de constitucionalidade tornou-se quase universalmente aceito. A legitimidade democrática da jurisdição constitucional tem sido assentada com base em dois fundamentos principais: a) a proteção dos direitos fundamentais, que correspondem ao mínimo ético e à reserva de justiça de uma comunidade política ${ }^{10}$, insuscetíveis de serem atropelados por deliberação política majoritária; e b) a proteção das regras do jogo democrático e dos canais de participação política de todos ${ }^{11}$. A maior parte dos países do mundo confere ao Judiciário e, mais particularmente à sua suprema corte ou corte constitucional, o status de sentinela contra o risco da tirania das maiorias ${ }^{12}$. Evita-se, assim, que possam deturpar o processo democrático ou oprimir as minorias. Há razoável consenso, nos dias atuais, de que o conceito de democracia transcende a ideia de governo da maioria, exigindo a incorporação de outros valores fundamentais.

Um desses valores fundamentais é o direito de cada indivíduo a igual respeito e consideração ${ }^{13}$, isto é, a ser tratado com a mesma dignidade dos

${ }^{8}$ A expressão se tornou clássica a partir da obra de Alexander Bickel. Cf. BICKEL, Alexander. The Least Dangerous Branch: the Supreme Court at the bar of Politics.

New Haven, CT: Yale University Press, 1986, p. 16 e ss. A primeira edição do livro é de 1962.

${ }^{9}$ E.g., WALDRON, Jeremy. The Core of the Case against Judicial Review. The Yale Law Journal, Vol. 115, 6, 2006; e TUSHNET, Mark. Taking the Constitution away from the Courts. Princeton, NJ: Princeton University Press, 1999.

${ }^{10}$ A equiparação entre direitos humanos e reserva mínima de justiça é feita por Robert Alexy em diversos de seus trabalhos. V., e.g., ALEXY, Robert. La Institucionalización de la Justicia. Trad. José Antonio Seoane, Eduardo Roberto Sodero e Pablo Rodríguez. Granada: Comares, 2005, p. 76.

${ }^{11}$ Para esta visão processualista do papel da jurisdição constitucional, v. ELY, John Hart. Democracy and Distrust: a Theory of Judicial Review. Cambridge, MA: Harvard University Press, 1980.

${ }^{12}$ A expressão foi utilizada por John Stuart Mill, em On Liberty: "A tirania da maioria é agora geralmente incluída entre os males contra os quais a sociedade precisa ser protegida (...)". MILL, John Stuart. On Liberty. London: Longmans, Green, Reader \& Dyer, 1874, p. 13.

${ }^{13}$ DWORKIN, Ronald. Taking Rights Seriously. Cambridge, MA: Harvard University Press, 1997, p. 181. A primeira edição é de 1977. 
demais - o que inclui ter os seus interesses e opiniões levados em conta. A democracia, portanto, para além da dimensão procedimental de ser o governo da maioria, possui igualmente uma dimensão substantiva, que inclui igualdade, liberdade e justiça. É isso que a transforma, verdadeiramente, em um projeto coletivo de autogoverno, em que ninguém é deliberadamente deixado para trás. Mais do que o direito de participação igualitária, democracia significa que os vencidos no processo político, assim como os segmentos minoritários em geral, não estão desamparados e entregues à própria sorte. Justamente ao contrário, conservam a sua condição de membros igualmente dignos da comunidade política ${ }^{14}$. Em quase todo o mundo, o guardião dessas promessas ${ }^{15}$ é a suprema corte ou o tribunal constitucional, por sua capacidade de ser um fórum de princípios ${ }^{16}$ - isto é, de valores constitucionais, e não de política - e de razão pública - isto é, de argumentos que possam ser aceitos por todos os envolvidos no debate ${ }^{17}$. Seus membros não dependem do processo eleitoral e suas decisões têm de fornecer argumentos normativos e racionais que a suportem.

Cumpre registrar que esse papel contramajoritário do Supremo Tribunal Federal tem sido exercido, como é próprio, com razoável parcimônia. De fato, nas situações em que não estejam em jogo direitos fundamentais e os pressupostos da democracia, a Corte deve ser deferente para com a liberdade de conformação do legislador e a razoável discricionariedade do administrador. Por isso mesmo, é relativamente baixo o número de dispositivos de leis federais efetivamente declarados inconstitucionais, sob a vigência da Constituição de $1988^{18}$. É certo que,

${ }^{14}$ Cf. MENDONÇA, Eduardo. A Democracia das Massas e a Democracia das Pessoas: um outro olhar sobre a Dificuldade Contramajoritária. 2014 Tese (Doutorado em Direito) - Universidade do Estado do Rio de Janeiro, Rio de Janeiro, 2014, p. 84. Tese de doutorado escrita sob minha orientação.

${ }^{15}$ A expressão consta do título do livro de GARAPON, Antoine. O Juiz e a

Democracia: o guardião das promessas. Rio de Janeiro, RJ: Revan, 1999.

${ }^{16}$ DWORKIN, Ronald. The Forum of Principle, New York University Law Review, Vol. 56, 469, 1981.

17 RAWLS, John. Political Liberalism. New York, NY: Columbia University Press, 2005. A primeira edição é de 1993.

${ }^{18}$ Com base em levantamento elaborado pela Secretaria de Gestão Estratégica, do Supremo Tribunal Federal, foi possível identificar 93 dispositivos de lei federal declarados inconstitucionais, desde o início de vigência da Constituição de 1988 - um número pouco expressivo, ainda mais quando se considera que foram editadas, no mesmo período, nada menos que 5.379 leis ordinárias federais, somadas a outras 88 leis complementares. 
em uma singularidade brasileira, existem alguns precedentes de dispositivos de emendas constitucionais cuja invalidade foi declarada pelo $\mathrm{STF}^{19}$. Mas, também aqui, nada de especial significação, em quantidade e qualidade. Anote-se, por relevante, que em alguns casos emblemáticos de judicialização de decisões políticas - como a legitimidade ou não das pesquisas com células-tronco embrionárias, a validade ou não de lei federal que previa ações afirmativas em favor de negros no acesso a universidades e a constitucionalidade do decreto do Presidente da República que demarcou uma extensa área do Estado de Roraima como reserva indígena - , a posição do Tribunal, em todos eles, foi de autocontenção e de preservação da decisão tomada pelo Congresso Nacional ou pelo Presidente da República.

Até aqui procurou-se justificar a legitimidade democrática do papel contramajoritário exercido pela jurisdição constitucional, bem como demonstrar que não há superposição plena entre o conceito de democracia e o princípio majoritário. Antes de analisar o tema da função representativa do STF e concluir o presente ensaio, cabe enfrentar uma questão complexa e delicada em todo o mundo, materializada na seguinte indagação: até que ponto é possível afirmar, sem apegar-se a uma ficção ou a uma idealização desconectada dos fatos, que os atos legislativos correspondem, efetivamente, à vontade majoritária?

\section{A Crise da Representação Política}

Há muitas décadas, em todo o mundo democrático, é recorrente o discurso acerca da crise dos parlamentos e das dificuldades da representação política. Da Escandinávia à América Latina, um misto de ceticismo, indiferença e insatisfação assinala a relação da sociedade civil com a classe política. Nos países em que o voto não é obrigatório, os índices de abstenção revelam o desinteresse geral. Em países de voto obrigatório, como o Brasil, um percentual muito baixo de eleitores é capaz

${ }_{19}$ V. STF, ADI 939/DF, Min. Rel. Sydney Sanches, Tribunal Pleno. Julgamento em: 15/12/1993; STF, ADI 1.946/DF, Min. Rel. Sydney Sanches, Tribunal Pleno. Julgamento em: 03/04/2003; STF, ADI 3.128/DF, Min. Rel. para Acórdão Cezar Peluso, Tribunal Pleno. Julgamento em: 18/08/2004; STF, ADI 2.356-MC/DF, Min. Rel. para Acórdão Ayres Britto, Tribunal Pleno. Julgamento em: 25/11/2010; STF, ADI 4.357/DF, Min. Rel. para Acórdão Luiz Fux, Tribunal Pleno. Julgamento em: 14/03/2013. STF, ADI 4.425/DF, Min. Rel. para Acórdão Luiz Fux, Tribunal Pleno. Julgamento em: $14 / 03 / 2013$. 
de se recordar em quem votou nas últimas eleições parlamentares. Disfuncionalidade, corrupção, captura por interesses privados são temas globalmente associados à atividade política. E, não obstante isso, em qualquer Estado democrático, política é um gênero de primeira necessidade. Mas as insuficiências da democracia representativa, na quadra atual, são excessivamente óbvias para serem ignoradas.

A consequência inevitável é a dificuldade de o sistema representativo expressar, efetivamente, a vontade majoritária da população. Como dito, o fenômeno é em certa medida universal. Nos Estados Unidos, cuja política interna tem visibilidade global, os desmandos do financiamento eleitoral, a indesejável infiltração da religião no espaço público e a radicalização de alguns discursos partidários deterioraram o debate público e afastaram o cidadão comum. Vicissitudes análogas acometem países da América Latina e da Europa, com populismos de esquerda, em uma, e de direita, em outra. No Brasil, por igual, vive-se uma situação delicada, em que a atividade política desprendeu-se da sociedade civil, que passou a vê-la com indiferença, desconfiança ou desprezo. Ao longo dos anos, a ampla exposição das disfunções do financiamento eleitoral, das relações oblíquas entre Executivo e parlamentares e do exercício de cargos públicos para benefício próprio revelou as mazelas de um sistema que gera muita indignação e poucos resultados. Em suma: a doutrina, que antes se interessava pelo tema da dificuldade contramajoritária dos tribunais constitucionais, começa a voltar atenção para o déficit democrático da representação política ${ }^{20}$.

Essa crise de legitimidade, representatividade e funcionalidade dos parlamentos gerou, como primeira consequência, em diferentes partes do mundo, um fortalecimento do Poder Executivo. Nos últimos anos, porém, e com especial expressão no Brasil, tem-se verificado uma expansão do Poder Judiciário e, notadamente, do Supremo Tribunal Federal. Em curioso paradoxo, o fato é que em muitas situações juízes e tribunais se tornaram mais representativos dos anseios e demandas sociais do que as instâncias políticas tradicionais. É estranho, mas vivemos uma quadra em que a sociedade se identifica mais com seus juízes do que com seus parlamentares. Um exemplo ilustra bem a afirmação: quando o Congresso Nacional aprovou as pesquisas com células-tronco embrionárias, o tema passou despercebido. Quando a lei

${ }^{20}$ V., e.g., GRABER, Mark. The Countermajoritarian Difficulty: From Courts to Congress to Constitutional Order. Annual Review of Law and Social Science, Vol. 4, 1, 2008. V., também, BARROSO, Luís Roberto. Neoconstitucionalismo e Constitucionalização do Direito (O Triunfo Tardio do Direito Constitucional no Brasil). Revista de Direito Administrativo, Vol. 240, 2005, p. 41. 
foi questionada no STF, assistiu-se a um debate nacional. É imperativo procurar compreender melhor este fenômeno, explorar-lhe eventuais potencialidades positivas e remediar a distorção que ele representa. A teoria constitucional ainda não elaborou analiticamente o tema, a despeito da constatação inevitável: a democracia já não flui exclusivamente pelas instâncias políticas tradicionais.

\section{O PAPEL REPRESENTATIVO DO SUPREMO TRIBUNAL FEDERAL}

A grande arte em política não é ouvir os que falam, é ouvir os que se calam.

- Etienne Lamy

Ao longo do texto procurou-se ressaltar a substantivação do conceito de democracia, que, além de não se identificar integralmente com o princípio majoritário, tem procurado novos mecanismos de expressão. Um deles foi a transferência de poder político - aí incluído certo grau de criação judicial do direito - para órgãos como o Supremo Tribunal Federal. O presente tópico procura explorar esse fenômeno, tanto na sua dinâmica interna quanto nas suas causas e consequências. No arranjo institucional contemporâneo, em que se dá a confluência entre a democracia representativa e a democracia deliberativa ${ }^{21}$, o exercício do poder e da autoridade é legitimado por votos e por argumentos. É fora de dúvida que o modelo tradicional de separação de Poderes, concebido no século XIX e que sobreviveu ao século XX, já não dá conta de justificar, em toda a extensão, a estrutura e funcionamento do constitucionalismo contemporâneo. Para utilizar um lugar comum, parodiando Antonio Gramsci, vivemos um momento em que o velho já morreu e novo ainda

\footnotetext{
${ }^{21}$ A ideia de democracia deliberativa tem como precursores autores como John Rawls, com sua ênfase na razão, e Jürgen Habermas, com sua ênfase na comunicação. Sobre democracia deliberativa, v., entre muitos, em língua inglesa, GUTMANN, Amy; THOMPSON, Dennis. Why Deliberative Democracy? Princeton, NJ: Princeton University Press, 2004; e, em português, SOUZA NETO, Cláudio Pereira de. Teoria Constitucional e Democracia Deliberativa: um estudo sobre o papel do Direito na garantia das condições para a cooperação na deliberação democrática. Rio de Janeiro, RJ: Renovar, 2006.
} 
não nasceu ${ }^{22}$.

A doutrina da dificuldade contramajoritária, estudada anteriormente, assenta-se na premissa de que as decisões dos órgãos eletivos, como o Congresso Nacional, seriam sempre expressão da vontade majoritária. E que, ao revés, as decisões proferidas por uma corte suprema, cujos membros não são eleitos, jamais seriam. Qualquer estudo empírico desacreditaria as duas proposições. Por numerosas razões, o Legislativo nem sempre expressa o sentimento da maioria ${ }^{23}$. Além do já mencionado déficit democrático resultante das falhas do sistema eleitoral e partidário, é possível apontar algumas outras. Em primeiro lugar, minorias parlamentares podem funcionar como veto players ${ }^{24}$, obstruindo o processamento da vontade da própria maioria parlamentar. Em outros casos, o autointeresse da Casa legislativa leva-a a decisões que frustram o sentimento popular. Além disso, parlamentos em todo o mundo estão sujeitos à captura eventual por interesses especiais, eufemismo que identifica o atendimento a interesses de certos agentes influentes do ponto de vista político ou econômico, ainda quando em conflito com o interesse coletivo ${ }^{25}$.

Por outro lado, não é incomum nem surpreendente que o Judiciário, em certos contextos, seja melhor intérprete do sentimento majoritário. Inúmeras razões contribuem para isso. Inicio por uma que é menos explorada pela doutrina em geral, mas particularmente significativa no Brasil. Juízes são recrutados, na primeira instância, mediante concurso público. Isso significa que pessoas vindas de diferentes origens sociais,

22 "A crise consiste precisamente no fato de que o velho está morrendo e o novo não pode nascer. Nesse interregno, uma grande variedade de sintomas mórbidos aparecem" (tradução livre). GRAMSCI, Antonio. Cuadernos del Carcel. Medellín: Era, 1981. V., também, entrevista do sociólogo Zigmunt Bauman, disponível em $<$ http://www.plurale.com.br/site/noticias-detalhes.php? cod=6029\&codSecao=6 $>$. ${ }^{23}$ Sobre o tema, v. LAIN, Corinna Barrett. Upside-Down Judicial Review. The Georgetown Law Review, Vol. 101, 1, 2012. V., também, KLARMAN, Michael. The Majoritarian Judicial Review: The Entrenchment Problem. The Georgetown Law Journal, Vol. 85, 3, 1997.

${ }^{24}$ Veto players são atores individuais ou coletivos com capacidade de parar o jogo ou impedir o avanço de uma agenda. Sobre o tema, v. ABRAMOVAY, Pedro. Separação de Poderes e Medidas Provisórias. Rio de Janeiro, RJ: Elsevier, 2012, p. 44 e s. ${ }^{25}$ Este tema tem sido objeto de estudo, nos Estados Unidos, por parte da chamada public choice theory, que procura desmistificar a associação entre lei e vontade da maioria. Para um resumo desses argumentos, v. BRANDÃO, Rodrigo. Supremacia Judicial versus Diálogos Constitucionais: a quem cabe a última palavra sobre o sentido da Constituição? Rio de Janeiro, RJ: Lumen Juris, 2012, p. 205. 
desde que tenham cursado uma Faculdade de Direito e tenham feito um estudo sistemático aplicado, podem ingressar na magistratura. Essa ordem de coisas produziu, ao longo dos anos, um drástico efeito democratizador do Judiciário. Por outro lado, o acesso a uma vaga no Congresso envolve um custo financeiro elevado, que obriga o candidato, com frequência, a buscar financiamentos e parcerias com diferentes atores econômicos e empresariais. Esse fato produz uma inevitável aliança com alguns interesses particulares. Por essa razão, em algumas circunstâncias, juízes são capazes de representar melhor - ou com mais independência - a vontade da sociedade. Poder-se-ia contrapor que este argumento não é válido para os integrantes do Supremo Tribunal Federal. Na prática, porém, a quase integralidade dos Ministros integrantes da Corte é composta por egressos de carreiras jurídicas cujo ingresso se faz por disputados concursos públicos ${ }^{26}$.

Diversas outras razões se acrescem a esta. Em primeiro lugar, juízes possuem a garantia da vitaliciedade. Como consequência, não estão sujeitos às circunstâncias de curto prazo da política eleitoral, nem tampouco, ao menos em princípio, a tentações populistas. Uma segunda razão é que os órgãos judiciais somente podem atuar por iniciativa das partes: ações judiciais não se instauram de ofício. Ademais, juízes e tribunais não podem julgar além do que foi pedido e têm o dever de ouvir todos os interessados. No caso do Supremo Tribunal Federal, além da atuação obrigatória do Procurador-Geral da República e do AdvogadoGeral da União em diversas ações, existe a possibilidade de convocação de audiências públicas e da atuação de amici curiae. Por fim, mas não menos importante, decisões judiciais precisam ser motivadas. Isso significa que, para serem válidas, jamais poderão ser um ato de pura vontade discricionária: a ordem jurídica impõe ao juiz de qualquer grau o dever de apresentar razões, isto é, os fundamentos e argumentos do seu raciocínio e convencimento.

Convém aprofundar um pouco mais este último ponto. Em uma visão

${ }^{26}$ Na composição de julho de 2014: Celso de Mello era integrante do Ministério Público de São Paulo. Gilmar Mendes e Joaquim Barbosa vieram do Ministério Público

Federal. Carmen Lúcia e Luís Roberto Barroso eram procuradores do Estado. Luiz Fux e Teori Zavascky proveem, respectivamente, da magistratura estadual e federal. Rosa Weber, da magistratura do trabalho. Os outros três Ministros, embora não concursados para ingresso nas instituições que integravam, vieram de carreiras vitoriosas: Marco Aurélio Mello (Procuradoria do Trabalho e, depois, Ministro do TST), Ricardo Lewandowski (Desembargador do Tribunal de Justiça de São Paulo, tendo ingressado na magistratura pelo quinto constitucional) e Dias Toffoli (Advogado-Geral da União). 
tradicional e puramente majoritária da democracia, ela se resumiria a uma legitimação eleitoral do poder. Por esse critério, o fascismo na Itália ou o nazismo na Alemanha poderiam ser vistos como democráticos, ao menos no momento em que se instalaram no poder e pelo período em que tiveram apoio da maioria da população. Aliás, por esse último critério, até mesmo o período Médici, no Brasil, passaria no teste. Não é uma boa tese. Além do momento da investidura, o poder se legitima, também, por suas ações e pelos fins visados ${ }^{27}$. Cabe aqui retomar a ideia de democracia deliberativa, que se funda, precisamente, em uma legitimação discursiva: as decisões políticas devem ser produzidas após debate público livre, amplo e aberto, ao fim do qual se forneçam as razões das opções feitas. Por isso se ter afirmado, anteriormente, que a democracia contemporânea é feita de votos e argumentos. Um insight importante nesse domínio é fornecido pelo jusfilósofo alemão Robert Alexy, que se refere à corte constitucional como representante argumentativo da sociedade. Segundo ele, a única maneira de reconciliar a jurisdição constitucional com a democracia é concebê-la, também, como uma representação popular. Pessoas racionais são capazes de aceitar argumentos sólidos e corretos. O constitucionalismo democrático possui uma legitimação discursiva, que é um projeto de institucionalização da razão e da correção ${ }^{28}$.

Cabe fazer algumas observações adicionais. A primeira delas de caráter terminológico. Se se admite a tese de que os órgãos representativos podem não refletir a vontade majoritária, decisão judicial que infirme um ato do Congresso pode não ser contramajoritária. O que ela será, invariavelmente, é contrarrepresentativa ${ }^{29}$, entendendo-se o parlamento como o órgão por excelência de representação popular. De parte isso, cumpre fazer um contraponto à assertiva, feita parágrafos atrás, de que juízes eram menos suscetíveis a tentações populistas. Isso não significa que estejam imunes a essa disfunção. Notadamente em uma época de julgamentos televisados, cobertura da imprensa e reflexos na

${ }^{27}$ V. MOREIRA NETO, Diogo de Figueiredo. Teoria do Poder, Parte I: Sistema de

Direito Político, Estudo Juspolítico do Poder. São Paulo, SP: Ed. Revista dos

Tribunais, 1992, p. 228-231, em que discorre sobre a legitimidade originária, corrente e finalística do poder político.

${ }^{28}$ V. ALEXY, Robert. Balancing, Constitutional Review, and Representation.

International Journal of Constitutional Law, Vol. 3, 4, 2005, p. 578 e ss.

${ }^{29}$ Tal particularidade foi bem captada por MENDONÇA, Eduardo. A Democracia das

Massas e a Democracia das Pessoas: um outro olhar sobre a Dificuldade

Contramajoritária. 2014 Tese (Doutorado em Direito) - Universidade do Estado do Rio de Janeiro, Rio de Janeiro, 2014, p. 213 e s.

2 JOURNAL OF INSTITUTIONAL STUDIES 2 (2016) 
opinião pública, o impulso de agradar a plateia é um risco que não pode ser descartado. Mas penso que qualquer observador isento testemunhará que esta não é a regra. É pertinente advertir, ainda, para um outro risco. Juízes são aprovados em concursos árduos e competitivos, que exigem longa preparação, constituindo quadros qualificados do serviço público. Tal fato pode trazer a pretensão de sobrepor uma certa racionalidade judicial às circunstâncias dos outros Poderes, cuja lógica de atuação, muitas vezes, é mais complexa e menos cartesiana. Por evidente, a arrogância judicial é tão ruim quanto qualquer outra, e há de ser evitada.

$\mathrm{O}$ fato de não estarem sujeitas a certas vicissitudes que acometem os dois ramos políticos dos Poderes não é, naturalmente, garantia de que as supremas cortes se inclinarão em favor das posições majoritárias da sociedade. A verdade, no entanto, é que uma observação atenta da realidade revela que é isso mesmo o que acontece. Nos Estados Unidos, décadas de estudos empíricos demonstram o ponto ${ }^{30}$. Também no Brasil tem sido assim. Em dois pronunciamentos relevantes, o Supremo Tribunal Federal chancelou a proibição do nepotismo nos três Poderes $^{31}$, em claro alinhamento com as demandas da sociedade em matéria de moralidade administrativa. A tese vencida era a de que somente o legislador poderia impor esse tipo de restrição ${ }^{32}$. Também ao apreciar a

${ }^{30}$ LAIN, Corinna Barrett. Upside-Down Judicial Review. The Georgetown Law

Review, Vol. 101, 1, 2012, p. 158. V., também, DAHL, Robert. Decision-making in a Democracy: the Supreme Court as a National Policy-Maker. Journal of Public Law, Vol. 6, 279, 1957, p. 285; e ROSEN, Jeffrey. The Most Democratic Branch: how the Courts serve America. New York, NY: Oxford University Press, 2006, p. xii: “Longe de proteger as minorias contra a tirania das maiorias ou contrabalançar a vontade do povo, os tribunais, ao longo da maior parte da história americana, têm se inclinado por refletir a visão constitucional das maiorias". Na mesma linha, como assinalado, v. TUSHNET, Mark. Taking the Constitution away from the Courts. Princeton, NJ: Princeton University Press, 1999, p. 153.

${ }^{31}$ Assim se deu no julgamento da ADC 12 e na edição da Súmula Vinculante no 13 , que proíbe a nomeação de parentes até o terceiro grau para cargos em comissão ou funções gratificadas. Cf. STF, ADC 12/DF, Min. Rel. Ayres Britto, Tribunal Pleno. Julgamento em: 16/02/2006.

32 Em defesa do ponto de vista de que o CNJ não teria o poder de impor tal vedação, v. STRECK, Lenio; SARLET, Ingo Wolfgang; CLÈVE, Clèmerson Mèrlin. Os Limites Constitucionais das Resoluções do Conselho Nacional de Justiça (CNJ) e do Conselho Nacional do Ministério Público (CNMP). Disponível em: $<$ http://www.egov.ufsc.br/portal/sites/default/files/anexos/15653-15654-1-PB.pdf $>$. Acesso em: 30 de janeiro de 2017. 
legitimidade da criação do Conselho Nacional de Justiça - CNJ como órgão de controle do Judiciário e ao afirmar a competência concorrente do Conselho para instaurar processos disciplinares contra magistrados, o STF atendeu ao anseio social pela reforma do Judiciário, apesar da resistência de setores da própria magistratura ${ }^{33}$. No tocante à fidelidade partidária, a posição do STF foi ainda mais arrojada, ao determinar a perda do mandato por parlamentar que trocasse de partido ${ }^{34}$. Embora tenha sofrido crítica por excesso de ativismo, é fora de dúvida que a decisão atendeu a um anseio social que não obteve resposta do Congresso. Outro exemplo: no julgamento, ainda não concluído, no qual se discute a legitimidade ou não da participação de empresas privadas no financiamento eleitoral, o STF, claramente espelhando um sentimento majoritário, sinaliza com a diminuição do peso do dinheiro no processo eleitoral ${ }^{35}$. A Corte acaba realizando, em fatias, de modo incompleto e sem possibilidade de sistematização, a reforma política que a sociedade clama.

Para além do papel puramente representativo, supremas cortes desempenham, ocasionalmente, o papel de vanguarda iluminista, encarregada de empurrar a história quando ela emperra. Trata-se de uma competência perigosa, a ser exercida com grande parcimônia, pelo risco democrático que ela representa e para que as cortes constitucionais não se transformem em instâncias hegemônicas. Mas, vez por outra, trata-se de papel imprescindível. Nos Estados Unidos, foi por impulso da Suprema Corte que se declarou a ilegitimidade da segregação racial nas escolas públicas, no julgamento de Brown v. Board of Education ${ }^{36}$. Na África do Sul, coube ao Tribunal Constitucional abolir a pena de morte ${ }^{37}$. Na Alemanha, o Tribunal Constitucional Federal deu a última palavra sobre a validade da criminalização da negação do holocausto ${ }^{38}$. A Suprema Corte de Israel reafirmou a absoluta proibição da tortura, mesmo na hipótese de interrogatório de suspeitos de terrorismo, em um ambiente

${ }_{33}$ STF, ADI 3.367/DF, Min. Rel. Cezar Peluso, Tribunal Pleno. Julgamento em:

13/04/2005; e STF, ADI 4.638/DF, Min. Rel. Marco Aurélio de Mello, Tribunal Pleno.

Julgamento em: 08/02/2012.

${ }_{34}$ STF, MS 26.604/DF, Min. Rel. Cármen Lúcia, Tribunal Pleno. Julgamento em:

04/10/2007.

${ }^{35}$ STF, ADI 4.650/DF, Min. Rel. Luiz Fux, Tribunal Pleno. Julgamento em: 30/10/2013.

36 Brown v. Board of Education, 347 U.S. 483 (1954).

${ }^{37}$ S v. Makwanyane and Another (CCT3/94) [1995] ZACC 3.

3890 BVerfGe 241 (1994). V. BRUGGER, Winfried. Ban on Or Protection of Hate Speech?

Some Observations Based on German and American Law. Tulane European \& Civil

Law Forum, Vol. 17, 1, 2002, p. 1.

2 JOURNAL OF INSTITUTIONAL STUDIES 2 (2016) 
social conflagrado, que se tornara leniente com tal prática ${ }^{39}$.

No Brasil, o Supremo Tribunal Federal equiparou as uniões homoafetivas às uniões estáveis convencionais, abrindo caminho para o casamento entre pessoas do mesmo sexo ${ }^{40}$. Talvez esta não fosse uma posição majoritária na sociedade, mas a proteção de um direito fundamental à igualdade legitimava a atuação. Semelhantemente se passou com a permissão para a interrupção da gestação de fetos anencefálicos ${ }^{41}$. São exemplos emblemáticos do papel iluminista da jurisdição constitucional. Nesses dois casos específicos, um fenômeno chamou a atenção. Em razão da natureza polêmica dos dois temas, uma quantidade expressiva de juristas se posicionou contrariamente às decisões - "não por serem contrários ao mérito, absolutamente não..." -, mas por entenderem se tratar de matéria da competência do legislador, e não do STF. Como havia direitos fundamentais em jogo, esta não parece ser a melhor posição. Ela contrapõe o princípio formal da democracia as maiorias políticas é que têm legitimidade para decidir - aos princípios materiais da igualdade e da dignidade da pessoa humana, favorecendo o primeiro em ambos os $\operatorname{casos}^{42}$. Coloca-se o procedimento acima do resultado, o que não parece um bom critério ${ }^{43}$.

Às vezes, ocorre na sociedade uma reação a certos avanços propostos pela suprema corte. Nos Estados Unidos, esse fenômeno recebe o nome

${ }^{39}$ Public Committee Against Torture in Israel v. The State of Israel \& The General Security Service. HCJ 5100/94 (1999). Disponível em:

$<$ http://elyon1.court.gov.il/files eng/94/000/051/a09/94051000.a09.pdf $>$. Acesso em: 30 de janeiro de 2017.

${ }^{40}$ STF, ADPF 132/RJ, Min. Rel. Ayres Britto, Tribunal Pleno. Julgamento em:

05/05/2011; e STF, ADI 4.277/DF, Min. Rel. Ayres Britto, Tribunal Pleno. Julgamento em: 05/05/2011.

${ }^{41}$ STF, ADPF 54/DF, Min. Rel. Marco Aurélio de Mello, Tribunal Pleno. Julgamento em: 09/04/2012.

${ }^{42}$ Sobre princípios formais e materiais, e critérios para a ponderação entre ambos, v. ALEXY, Robert. Princípios formais. In: Alexandre Travessoni Gomes Trivisonno, Aziz Tuffi Saliba e Mônica Sette Lopes (Orgs.). Princípios Formais: e Outros Aspectos da

Teoria Discursiva do Direito. São Paulo, SP: Editora Forense, 2014. Na p. 20, escreveu Alexy: "Admitir uma competência do legislador democraticamente legitimado de interferir em um direito fundamental simplesmente porque ele é democraticamente legitimado destruiria a prioridade da constituição sobre a legislação parlamentar ordinária".

${ }^{43}$ Como se verifica do tópico I do texto, Mark Tushnet tem uma posição diferente em relação a esse ponto. 
de backlash. Um caso paradigmático de reação do Legislativo se deu contra o julgamento de Furman v. Georgia ${ }^{44}$, em 1972, no qual a Suprema Corte considerou inconstitucional a pena de morte, tal como aplicada em 39 Estados da Federação ${ }^{45}$. O fundamento principal era o descritério nas decisões dos júris e o impacto desproporcional sobre as minorias. Em 1976, no entanto, a maioria dos Estados havia aprovado novas leis sobre pena de morte, contornando o julgado da Suprema Corte. Em Gregg v. Georgia ${ }^{46}$, a Suprema Corte manteve a validade da nova versão da legislação penal daquele Estado. Também em Roe v. Wade ${ }^{47}$, a célebre decisão que descriminalizou o aborto, as reações foram imensas, até hoje dividindo opiniões de maneira radical ${ }^{48}$. No Brasil, houve alguns poucos casos de reação normativa a decisões do Supremo Tribunal Federal, como, por exemplo, em relação ao foro especial para certas autoridades ${ }^{4}$, às taxas municipais de iluminação pública ${ }^{50}$, à progressividade das alíquotas do imposto sobre propriedade urbana ${ }^{51}$, à cobrança de contribuição previdenciária de inativos ${ }^{52}$ e à definição do número de

${ }^{44}$ Furman v. Georgia, 408 U.S. 238 (1972).

${ }_{45}$ Para um estudo da questão, v. LAIN, Corinna Barrett. Upside-Down Judicial

Review. The Georgetown Law Review, Vol. 101, 1, 2012.

${ }^{46}$ Gregg v. Georgia, 428 U.S. 153 (1976).

${ }^{47}$ Roe v. Wade, 410 U.S. 113 (1973).

${ }^{48}$ Sobre o tema, v. POST, Robert; SIEGEL, Reva. Roe Rage: Democratic Constitutionalism and Backlash. Harvard Civil Rights-Civil Liberties Law Review, Vol. 42, 2, 2007.

${ }^{49} \mathrm{~A}$ Lei $\mathrm{n}^{\circ}$ 10.628/02 foi uma resposta legislativa à decisão do STF no Inq 687-QO. No entanto, em um caso singular de reação jurisdicional à reação legislativa, o STF declarou a inconstitucionalidade da lei, afirmando que não caberia ao Congresso, mediante lei ordinária, rever a interpretação do texto constitucional dada pelo Tribunal. Cf. STF, Inq 687/SP-QO, Min. Rel. Sydney Sanches, Tribunal Pleno. Julgamento em: 25/08/1999; e STF, ADI 2.797/DF, Min. Rel. Sepúlveda Pertence, Tribunal Pleno. Julgamento em: 15/09/2005.

${ }^{50}$ A Emenda Constitucional nº 39/02 superou o entendimento que fora fixado pelo STF no julgamento do STF, RE 233.332/RJ, Min. Rel. Ilmar Galvão, Tribunal Pleno. Julgamento em: 10/03/1999.

${ }^{51}$ A Emenda Constitucional n ${ }^{\circ}$ 29/2000 superou o entendimento da Corte e admitiu expressamente a progressividade.

52 A Emenda Constitucional no 41/03 superou o entendimento que fora firmado no julgamento da STF, ADI 2.010/DF, Min. Rel. Celso de Mello, Tribunal Pleno. Julgamento em: 11/03/2004. 
vereadores das câmaras municipais ${ }^{53}$.

Em favor da tese que se vem sustentando ao longo do presente trabalho, acerca do importante papel democrático da jurisdição constitucional, é possível apresentar uma coleção significativa de decisões do Supremo Tribunal Federal que contribuíram para o avanço social no Brasil. Todas elas têm natureza constitucional, mas produzem impacto em um ramo específico do Direito, como enunciado abaixo:

a. Direito civil: proibição da prisão por dívida no caso de depositário infiel, reconhecendo a eficácia e prevalência do Pacto de San Jose da Costa Rica em relação ao direito interno.

b. Direito penal: declaração da inconstitucionalidade da proibição de progressão para regime mais favorável de cumprimento de pena, em caso de crimes hediondos e equiparáveis.

c. Direito administrativo: vedação do nepotismo nos três Poderes.

d. Direito à saúde: determinação de fornecimento de gratuito de medicamentos necessários ao tratamento da AIDS em pacientes sem recursos financeiros.

e. Direito à educação: direito à educação infantil, aí incluídos o atendimento em creche e o acesso à pré-escola, reconhecendo o dever do Poder Público de dar efetividade a esse direito.

f. Direitos políticos: proibição de livre mudança de partido após a eleição, sob pena de perda do mandato, por violação ao princípio democrático.

g. Direitos dos trabalhadores públicos: regulamentação, por via de mandado de injunção, do direito de greve dos servidores e trabalhadores do serviço público.

h. Direito dos deficientes físicos: direito de passe livre no sistema de transporte coletivo interestadual a pessoas portadoras de deficiência, comprovadamente carentes.

${ }^{53}$ A Emenda Constitucional no 58/09 superou em parte o entendimento que fora firmado no julgamento do STF, RE 197.917/SP, Min. Rel. Maurício Corrêa, Tribunal Pleno. Julgamento em: 06/06/2002. 
i. Proteção das minorias:

(i) Judeus: a liberdade de expressão não inclui manifestações de racismo, aí incluído o antissemitismo.

(ii) Negros: validação de ações afirmativas em favor de negros, pardos e índios.

(iii) Homossexuais: equiparação das relações homoafetivas às uniões estáveis convencionais e direito ao casamento civil.

(iv) Comunidades indígenas: demarcação da reserva indígena Raposa Serra do Sol em área contínua.

j. Liberdade de pesquisa científica: declaração da constitucionalidade das pesquisas com células-tronco embrionárias.

k. Direito das mulheres: direito à antecipação terapêutica do parto em caso de feto anencefálico; constitucionalidade da Lei Maria da Penha, que reprime a violência doméstica contra a mulher.

Três últimos comentários antes de encerrar. Primeiro: a jurisdição constitucional, como se procurou demonstrar acima, tem servido bem ao país. A preocupação com abusos por parte de juízes e tribunais não é infundada, e é preciso estar preparado para evitar que ocorram ${ }^{54}$. Porém, no mundo real, são muito limitadas as decisões do Supremo Tribunal Federal às quais se possa imputar a pecha de haverem ultrapassado a fronteira aceitável. E, nos poucos casos em que isso ocorreu, o próprio Tribunal cuidou de remediar ${ }^{55}$. Portanto, não se deve desprezar, por um temor imaginário, as potencialidades democráticas e civilizatórias de uma corte constitucional. A crítica à atuação do STF, desejável e legítima em uma sociedade plural e aberta, provem mais de atores insatisfeitos com alguns resultados e de um nicho acadêmico minoritário, que opera sobre premissas teóricas diversas das que vão aqui enunciadas. A

54 Para uma reflexão sobre o tema, tendo como marco teórico a teoria dos sistemas, de Niklas Luhmann, v. CAMPILONGO, Celso Fernandes. Política, Sistema Jurídico e Decisão Judicial. São Paulo, SP: Max Limonad, 2002, p. 63.

${ }_{55}$ No julgamento envolvendo a demarcação da Terra Indígena Raposa Serra do Sol, em embargos de declaração, foi restringido o alcance das denominadas "condicionantes" ali estabelecidas, para explicitar que não vinculavam, prospectivamente, novas demarcações. V. STF, ED-Pet 3.388/RR, Min. Rel. Roberto Barroso, Tribunal Pleno. Julgamento em: 23/10/2013. 
propósito, cabe formular uma pergunta crucial ${ }^{56}$ : o argumento de que a jurisdição constitucional tem atuado em padrões antidemocráticos não deveria vir acompanhado de uma insatisfação popular com o papel desempenhado pelo Supremo Tribunal Federal? O que dizer, então, se ocorre exatamente o contrário: no Brasil e no mundo, os índices de aprovação que ostenta a corte constitucional costumam estar bem acima dos do Legislativo ${ }^{57}$. Por certo não se devem extrair desse fato conclusões precipitadas nem excessivamente abrangentes. Porém, uma crítica formulada com base em uma visão formal da democracia, mas sem povo, não deve impressionar.

O segundo comentário é intuitivo. Como já se teve oportunidade de afirmar diversas vezes, decisão política, como regra geral, deve ser tomada por quem tem voto. Portanto, o Poder Legislativo e o chefe do Poder Executivo têm uma preferência geral prima facie para tratar de todas as matérias de interesse do Estado e da sociedade. E, quando tenham atuado, os órgãos judiciais devem ser deferentes para com as escolhas legislativas ou administrativas feitas pelos agentes públicos legitimados pelo voto popular. A jurisdição constitucional somente deve se impor, nesses casos, se a contrariedade à Constituição for evidente, se houver afronta a direito fundamental ou comprometimento dos pressupostos do Estado democrático. Porém, como o leitor terá intuído até aqui, a jurisdição constitucional desempenha um papel de maior destaque quando o Poder Legislativo não tenha atuado. E nas lacunas normativas ou nas omissões inconstitucionais que o STF assume um papel de eventual protagonismo. Como consequência, no fundo, é o próprio Congresso que detém a decisão final, inclusive sobre o nível de judicialização da vida.

Merece registro incidental, antes de encerrar o presente trabalho, um fenômeno conhecido na doutrina como diálogo constitucional ou diálogo institucional ${ }^{58}$. Embora a corte constitucional ou corte suprema seja o

${ }^{56}$ V. MENDONÇA, Eduardo. A Democracia das Massas e a Democracia das Pessoas: um outro olhar sobre a Dificuldade Contramajoritária. 2014 Tese (Doutorado em Direito) - Universidade do Estado do Rio de Janeiro, Rio de Janeiro, 2014, p. 19-20

${ }^{57}$ Segundo pesquisa do IBOPE, realizada em 2012, o índice de confiança dos brasileiros no STF é de 54 pontos (em uma escala de 0 a 100). O do Congresso é 39 pontos. V. $<$ http://www.conjur.com.br/2012-dez-24/populacao-confia-stf-congresso-nacionalibope $>$. Acesso em: 30 de janeiro de 2017.

${ }^{58}$ A expressão tem origem na doutrina canadense. V. HOGG, Peter; BUSHELL, Allison. The Charter Dialogue between Courts and Legislatures (Or Perhaps the 
intérprete final da Constituição em cada caso, três situações dignas de nota podem subverter ou atenuar esta circunstância, a saber: a) a interpretação da Corte pode ser superada por ato do Parlamento ou do Congresso, normalmente mediante emenda constitucional; $b$ ) a Corte pode devolver a matéria ao Legislativo, fixando um prazo para a deliberação ou c) a Corte pode conclamar o Legislativo a atuar, o chamado "apelo ao legislador". Na experiência brasileira existem diversos precedentes relativos à primeira hipótese, como no caso do teto remuneratório dos servidores públicos ${ }^{59}$ e da base de cálculo para incidência de contribuição previdenciária ${ }^{60}$, além dos já referidos anteriormente nesse mesmo tópico.

Em relação à segunda hipótese, referente à fixação de prazo para o Congresso legislar, há precedentes em relação à criação de Municípios ${ }^{61}$ ou à reformulação dos critérios adotados no Fundo de Participações dos Estados $^{62}$, embora nem sempre se dê o adequado cumprimento dentro do período demarcado pela decisão. Por fim, relativamente à terceira hipótese, por muitos anos foi esse o sentido dado pela jurisprudência do STF ao mandado de injunção ${ }^{63}$. Um caso muito significativo de diálogo institucional informal se deu em relação ao art. $7^{\circ}$, I da Constituição, que prevê a edição de lei complementar disciplinando a indenização compensatória contra a despedida arbitrária ou sem justa causa de um trabalhador. No julgamento de mandado de injunção, o plenário do STF

Charter of Rights Isn't Such a Bad Thing after All). Osgoode Hall Law Journal, Vol. 35, $1,1997$.

59 STF, ADI 14/DF, Min. Rel. Celio Borja, Tribunal Pleno. Julgamento em: 13/09/1989. No início da vigência da Constituição de 1988, o STF entendeu que o teto remuneratório do art. 37, XI não se aplicava às "vantagens pessoais", frustrando, na prática, a contenção dos abusos nessa matéria. Foram necessárias duas emendas

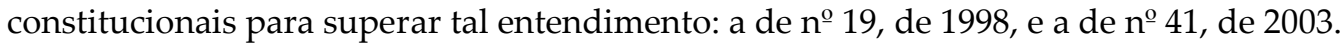
${ }^{60}$ STF, RE 166.772/RS, Min. Rel. Marco Aurélio de Mello, Tribunal Pleno. Julgamento em: 12/05/1994.

${ }^{61}$ STF, ADI 2.240/BA, Min. Rel. Eros Grau, Tribunal Pleno. Julgamento em: 09/05/2007. ${ }^{62} \mathrm{STF}, \mathrm{ADI}$ 3.682/MT, Min. Rel. Gilmar Mendes, Tribunal Pleno. Julgamento em: 09/05/2007. Neste caso, o STF fixou o prazo de 18 meses para o Congresso Nacional sanar a omissão relativamente à edição da lei complementar exigida pelo art. $18, \S 4^{\circ}$ da CF, tida como indispensável para a criação de Municípios por lei estadual.

${ }^{63} \mathrm{O}$ mandado de injunção é uma ação criada pela Constituição brasileira destinada a remediar omissões legislativas inconstitucionais. Por largo período, o STF entendeu que a única decisão possível em mandado de injunção era comunicar ao Congresso Nacional seu estado de mora e omissão. Posteriormente, o Tribunal passou a criar ele próprio, normalmente por analogia com alguma lei existente, a norma faltante. 
deliberou que iria fixar, ele próprio, o critério indenizatório, tendo em vista a omissão de mais de duas décadas do Congresso em fazê-lo ${ }^{64}$. Diante de tal perspectiva, o Congresso aprovou em tempo recorde a Lei $\mathrm{n}^{\mathrm{o}}$ 12.506/2011, provendo a respeito.

Mais recentemente, dois casos de diálogo institucional tiveram lugar. Ao decidir ação penal contra um Senador da República, o STF, por maioria apertada de votos, interpretou o art. 55 , VI e seu $\S 2^{\underline{0}}$ no sentido de caber à Casa legislativa decretar a perda do mandato de parlamentar que sofresse condenação criminal transitada em julgado ${ }^{65}$. Ministros que afirmaram a posição vencedora registraram sua crítica severa à fórmula imposta pela Constituição, instando o Congresso a revisitar o tema ${ }^{66}$. Pouco tempo após o julgamento, o Senado Federal aprovou Proposta de Emenda Constitucional superadora desse tratamento deficiente da matéria. Em final de 2014, a Proposta ainda se encontrava em tramitação na Câmara. Em outro caso, um Deputado Federal foi condenado a mais de 13 anos de prisão, em regime inicial fechado ${ }^{67}$. Submetida a questão da perda do seu mandato à Câmara dos Deputados, a maioria deliberou não cassá-lo. Em mandado de segurança impetrado contra esta decisão, foi concedida liminar pelo relator, sob o fundamento de que em caso de prisão em regime fechado, a perda do mandato deveria se dar por declaração da Mesa e não por deliberação política do Plenário ${ }^{68}$. Antes do julgamento do mérito do mandado de segurança, a Câmara dos Deputados suprimiu a previsão de voto secreto na matéria e deliberou pela cassação.

O que se deduz desse registro final é que o modelo vigente não pode ser caracterizado como de supremacia judicial. O Supremo Tribunal Federal tem a prerrogativa de ser o intérprete final do direito, nos casos que são a ele submetidos, mas não é o dono da Constituição. Justamente ao contrário, o sentido e o alcance das normas constitucionais são fixados em interação com a sociedade, com os outros Poderes e com as

${ }^{64}$ STF, MI 943/DF, Min. Rel. Gilmar Mendes, Tribunal Pleno. Julgamento em:

06/02/2013.

${ }_{65}$ STF, AP 565/RO, Min. Rel. Carmen Lúcia, Tribunal Pleno. Julgamento em: 18/09/2014 (caso Ivo Cassol).

${ }^{66}$ V. meu voto no STF, MS 32.326/DF, Min. Rel. Roberto Barroso, Tribunal Pleno.

Julgamento em: 02/09/2013.

${ }_{67}$ STF, AP 396/RO, Min. Rel. Carmen Lúcia, Tribunal Pleno. Julgamento em: 11/01/2013

(caso Natan Donadon).

68 STF, MS 32.326/DF, Min. Rel. Roberto Barroso, Tribunal Pleno. Julgamento em:

02/09/2013.

2 JOURNAL OF INSTITUTIONAL STUDIES 2 (2016) 
instituições em geral. A perda de interlocução com a sociedade, a eventual incapacidade de justificar suas decisões ou de ser compreendido, retiraria o acatamento e a legitimidade do Tribunal. Por outro lado, qualquer pretensão de hegemonia sobre os outros Poderes sujeitaria o Supremo a uma mudança do seu desenho institucional ou à superação de seus precedentes por alteração no direito, competências que pertencem ao Congresso Nacional. Portanto, o poder do Supremo Tribunal Federal tem limites claros. Na vida institucional, como na vida em geral, ninguém é bom demais e, sobretudo, ninguém é bom sozinho.

\section{CONCLUSÃO}

Nas décadas que se seguiram ao final da Segunda Guerra Mundial, verificou-se uma vertiginosa ascensão institucional do Poder Judiciário e da jurisdição constitucional. Não seria exagero afirmar que prevaleceu, em diversas partes do mundo, o modelo americano de constitucionalismo, com suas características de centralidade da Constituição, controle judicial de constitucionalidade e judicialização das controvérsias envolvendo direitos fundamentais. No presente texto, procurei demonstrar que cortes supremas - como o Supremo Tribunal Federal brasileiro, por exemplo - passaram a desempenhar, simultaneamente ao papel contramajoritário tradicional, uma função representativa, pela qual atendem a demandas sociais que não foram satisfeitas pelo processo político majoritário. Por evidente, no desempenho de tal atribuição, o juiz constitucional não está autorizado a impor a suas próprias convicções. Pautado pelo material jurídico relevante (normas, doutrinas, precedentes), pelos princípios constitucionais e pelos valores civilizatórios, cabe-lhe interpretar o sentimento social, o espírito de seu tempo e o sentido da história. Com a dose certa de prudência e de ousadia.

Como se percebe claramente, sou um defensor da jurisdição constitucional. A meu crédito, tenho essa posição desde muito antes de me tornar juiz constitucional. Acho que ela desempenha um papel relevante mesmo em democracias maduras, como Estados Unidos, Alemanha ou Canadá. Mas considero-a ainda mais importante em países de redemocratização recente ou de democratização tardia. Nesses Estados, como é comum, o processo político majoritário não consegue satisfazer plenamente as demandas sociais, em razão de distorções históricas na distribuição de poder e riqueza. Por certo, não se deve viver a ilusão de que o Judiciário seja imune a essas distorções. Porém, circunstâncias associadas ao modo de investidura de seus membros, às 
suas garantias institucionais e ao tipo de relação que mantêm com a sociedade (que não é ligada ao voto ou a objetivos de curto prazo) potencializa sua aptidão para o uso da razão e a proteção dos direitos fundamentais. Por evidente, a condição imprescindível é que consiga escapar da política ordinária - como tem sido, felizmente, o caso do Brasil.

Desnecessário enfatizar que esta é uma visão diferente da que Mark Tushnet sustentou em alguns de seus escritos ${ }^{69}$. Porém, em relação a inúmeras outras matérias, conexas ou não com a jurisdição constitucional, temos posições totalmente afinadas. Não é difícil ilustrar esta afirmação com alguns exemplos. Tal como ele, considero que, em uma democracia, política é gênero de primeira necessidade. Tribunais não devem abafar a voz das ruas, nem desconsiderar o papel do Congresso como uma instância privilegiada do debate público. Penso, igualmente, que decisões políticas, em linha de princípio, devem ser tomadas por quem tem voto. Ademais, mesmo quando se admita que a corte suprema dê a última palavra sobre o sentido da Constituição, ela deve ser capaz de levar em conta as aspirações das forças sociais e das outras instituições políticas. Não se trata de uma corte de si própria. Por fim, em muitas situações, será mais construtivo e democrático que a jurisdição constitucional adote uma postura de moderação, optando pelo diálogo institucional em lugar da imposição de sua visão. Sou convencido de que Tushnet endossaria todas essas ideias.

Em qualquer caso, na concordância ou na divergência, o que é fora de dúvida é que Mark Tushnet é um pensador denso, vigoroso e criativo, que influenciou de modo significativo a teoria constitucional contemporânea e várias gerações de estudiosos.

\section{REFERÊNCIAS}

\section{ABRAMOVAY, Pedro. Separação de Poderes e Medidas Provisórias. Rio de Janeiro, RJ: Elsevier, 2012.}

${ }^{69}$ Muito embora, em Weak courts, strong rights, ele tenha atenuado sua posição anterior de que as questões constitucionais devessem ser completamente retiradas dos tribunais. Cf. TUSHNET, Mark. Weak Courts, Strong Rights: Judicial Review and Social Welfare Rights in Comparative Constitutional Law. Princeton, NJ: Princeton University, 2008. 
ALEXY, Robert. Balancing, Constitutional Review, and Representation. International Journal of Constitutional Law, Vol. 3, 4, 2005.

ALEXY, Robert. La Institucionalización de la Justicia. Trad. José Antonio Seoane, Eduardo Roberto Sodero e Pablo Rodríguez. Granada: Comares, 2005.

ALEXY, Robert. Princípios formais. In: Alexandre Travessoni Gomes Trivisonno, Aziz Tuffi Saliba e Mônica Sette Lopes (Orgs.). Princípios Formais: e Outros Aspectos da Teoria Discursiva do Direito. São Paulo, SP: Editora Forense, 2014.

BARROSO, Luís Roberto. Neoconstitucionalismo e Constitucionalização do Direito (O Triunfo Tardio do Direito Constitucional no Brasil). Revista de Direito Administrativo, Vol. 240, 2005.

BRANDÃO, Rodrigo. Supremacia Judicial versus Diálogos Constitucionais: a quem cabe a última palavra sobre o sentido da Constituição? Rio de Janeiro, RJ: Lumen Juris, 2012.

BICKEL, Alexander. The Least Dangerous Branch: the Supreme Court at the bar of Politics. New Haven, CT: Yale University Press, 1986.

BRUGGER, Winfried. Ban on Or Protection of Hate Speech? Some Observations Based on German and American Law. Tulane European \& Civil Law Forum, Vol. 17, 1, 2002.

CAMPILONGO, Celso Fernandes. Política, Sistema Jurídico e Decisão Judicial. São Paulo, SP: Max Limonad, 2002.

DAHL, Robert. Decision-making in a Democracy: the Supreme Court as a National Policy-Maker. Journal of Public Law, Vol. 6, 279, 1957. 
DWORKIN, Ronald. Taking Rights Seriously. Cambridge, MA:

Harvard University Press, 1997.

DWORKIN, Ronald. The Forum of Principle, New York University Law Review, Vol. 56, 469, 1981.

ELY, John Hart. Democracy and Distrust: a Theory of Judicial Review. Cambridge, MA: Harvard University Press, 1980.

FERRAJOLI, Luigi. Pasado y futuro Del Estado de Derecho. In: Miguel Carbonell (Coord.). Neoconstitucionalismo(s). Madrid: Editora Trotta, 2003.

GARAPON, Antoine. O Juiz e a Democracia: o guardião das promessas. Rio de Janeiro, RJ: Revan, 1999.

GRABER, Mark. The Countermajoritarian Difficulty: From Courts to Congress to Constitutional Order. Annual Review of Law and Social Science, Vol. 4, 1, 2008.

GRAMSCI, Antonio. Cuadernos del Carcel. Medellín: Era, 1981.

GUTMANN, Amy; THOMPSON, Dennis. Why Deliberative Democracy? Princeton, NJ: Princeton University Press, 2004.

HOGG, Peter; BUSHELL, Allison. The Charter Dialogue between Courts and Legislatures (Or Perhaps the Charter of Rights Isn't Such a Bad Thing after All). Osgoode Hall Law Journal, Vol. 35, 1, 1997.

KLARMAN, Michael. The Majoritarian Judicial Review: The Entrenchment Problem. The Georgetown Law Journal, Vol. 85, 3, 1997.

LAIN, Corinna Barrett. Upside-Down Judicial Review. The Georgetown Law Review, Vol. 101, 1, 2012. 
MENDONÇA, Eduardo. A Democracia das Massas e a Democracia das Pessoas: um outro olhar sobre a Dificuldade Contramajoritária. 2014 Tese (Doutorado em Direito) - Universidade do Estado do Rio de Janeiro, Rio de Janeiro, 2014.

MOREIRA NETO, Diogo de Figueiredo. Teoria do Poder, Parte I: Sistema de Direito Político, Estudo Juspolítico do Poder. São Paulo, SP: Ed. Revista dos Tribunais, 1992.

POST, Robert; SIEGEL, Reva. Roe Rage: Democratic Constitutionalism and Backlash. Harvard Civil Rights-Civil Liberties Law Review, Vol. 42, 2, 2007.

RAWLS, John. Political Liberalism. New York, NY: Columbia University Press, 2005.

ROSEN, Jeffrey. The Most Democratic Branch: how the Courts serve America. New York, NY: Oxford University Press, 2006.

SOUZA NETO, Cláudio Pereira de. Teoria Constitucional e Democracia Deliberativa: um estudo sobre o papel do Direito na garantia das condições para a cooperação na deliberação democrática. Rio de Janeiro, RJ: Renovar, 2006.

STRECK, Lenio; SARLET, Ingo Wolfgang; CLÈVE, Clèmerson Mèrlin. Os Limites Constitucionais das Resoluções do Conselho Nacional de Justiça (CNJ) e do Conselho Nacional do Ministério Público (CNMP). Disponível em:

$<$ http://www.egov.ufsc.br/portal/sites/default/files/anexos/15653-156541-PB.pdf $>$. Acesso em: 30 de janeiro de 2017.

TUSHNET, Mark. Taking the Constitution away from the Courts. Princeton, NJ: Princeton University Press, 1999. 
TUSHNET, Mark. Weak Courts, Strong Rights: Judicial Review and Social Welfare Rights in Comparative Constitutional Law. Princeton, NJ: Princeton University, 2008.

TUSHNET, Mark. Why the Constitution matters. New Haven, CN: Yale University Press, 2010.

WALDRON, Jeremy. The Core of the Case against Judicial Review. The Yale Law Journal, Vol. 115, 6, 2006.

ZAGREBELSKY, Gustavo. El Derecho Dúctil: Ley, Derechos, Justicia. 6 ${ }^{\mathrm{a}}$ ed. Madrid: Editora Trotta, 2005.

A Razão Sem Voto: a Função Representativa e Majoritária das Cortes Constitucionais Reason without Vote: the Representative and Majoritarian Function of Constitutional Courts Submetido em: 2016-12-27 